\title{
Hepatitis C: The juggernaut rolls on unchecked
}

\author{
Morris Sherman PhD FRCPC MB
}

$I^{n}$ $\mathrm{n}$ this issue of The Canadian Journal of Gastroenterology, Myers et al (pages 381-387) have documented a steady increase in hospital costs associated with the management of chronic hepatitis $\mathrm{C}$. This is a result of an increase in the number of hospitalizations for hepatitis C, increases in in-hospital mortality and increased lengths of stay. They reviewed administrative database information from their local hospital authorities in Calgary. The review was limited to inpatient services and did not capture the increase in costs associated with outpatient services and costs of medication. These data are consistent with the notion that the morbidity associated with hepatitis $\mathrm{C}$ is rising. This has been difficult to measure, although there are data suggesting that the mortality from hepatitis $\mathrm{C}$ is rising, so it would not be surprising to find increasing morbidity. For example, in 1979, the age-standardized mortality rate related to non- $A$, non-B hepatitis (mainly hepatitis $C$ ) was 0.12 in a population of 100,000 , but in 1997 the mortality rate was 0.41 in a population of 100,000 (1).

Two important points flow from the study by Myers et al. First, as with any illness requiring hospitalization, the costs are likely to be substantial. In this regard, the bigger question is whether hepatitis $\mathrm{C}$ is more expensive than any other chronic illness. Patients who die from hepatitis C-related conditions do not accrue costs related to terminal care of other diseases. Therefore, to determine whether caring for a patient with chronic hepatitis $\mathrm{C}$ costs more than caring for patients with diseases such as diabetes, hypercholesterolemia or any other chronic disease that eventually causes death requires a control group that does not have hepatitis C. This information is not yet available.

The second major point is that the incidence of complications and the mortality rate related to hepatitis $\mathrm{C}$ may be rising more quickly than predicted. Zou et al (2) predicted a doubling of these outcomes over the period from 1998 to 2008. In this issue, Myers et al find that the rates have increased fourfold over the decade of their study. Remis et al (3) have also predicted more or less a doubling of hepatitis C-related complications over the next one to two decades. The analyses do not take into account the effects of treatment. Hepatitis $\mathrm{C}$ is a disease that is both preventable and treatable. Thus, the increase in mortality rates and the increase in costs are theoretically preventable. Current therapy can, under ideal circumstances, cure approximately $50 \%$ of all infected individuals. Because the current treatment has been available for five to six years, one question to ask is - why are we not seeing a decrease in morbidity (reflected as decreasing hospital costs)?

Hepatitis $\mathrm{C}$ has slipped out of the national limelight in the recent past. Although this is an important disease, in the 1990s, public attention was focused on it for the wrong reasons. Hepatitis $\mathrm{C}$ hit the headlines because of the issue of compensation for those who acquired hepatitis $\mathrm{C}$ from transfusion of blood and blood products. The patient-and media-driven furor and the resulting political reaction over the ensuing years cost the Canadian taxpayers more than $\$ 2$ billion to provide compensation. One could argue that transfusion was a life-saving procedure in many, if not most instances. Hepatitis $\mathrm{C}$ was a recognized, unpreventable complication of transfusion in those days (known then as post-transfusion or non-A, non-B hepatitis), just as myocardial infarction is a recognized and often unpreventable complication of coronary revascularization procedures. Why then should patients who contracted hepatitis $\mathrm{C}$ be compensated? Although the Red Cross may have been slow to safeguard the blood supply against HIV, they acted immediately to protect the blood supply against hepatitis $\mathrm{C}$ by introducing hepatitis $\mathrm{C}$ testing of donor blood as soon as the test became available. The argument revolved around whether alanine aminotransferase testing of donated blood in Canada would have decreased the risk of post-transfusion hepatitis, as it did in America. There were valid arguments for why this might not be the case; for example, the rate of post-transfusion hepatitis in Canada was much lower than in America, and measures to protect the blood pool against HIV had reduced the risk of post-transfusion hepatitis in Canada even further. It subsequently transpired that alanine aminotransferase testing would have reduced the post-transfusion hepatitis rate, but this information only became available after anti-hepatitis $\mathrm{C}$ virus testing was instituted (3). The legal case against governments and the Red Cross was never tested in court; instead the class action suits were settled, presumably for political reasons.

This attention also had the unfortunate effect of deflecting the focus from the vast majority of patients with hepatitis $C$ whose disease was not acquired by transfusion. Only approximately $15 \%$ of hepatitis C cases in Canada are transfusionrelated (4). Thus, $\$ 2$ billion has been spent on $15 \%$ of the patients with hepatitis $\mathrm{C}$, and very little of it was spent on medical services. Hopefully, information such as that provided by Myers et al will refocus public attention on hepatitis $\mathrm{C}$ for the right reasons - namely, that this is a potentially curable disease that currently afflicts approximately 250,000 Canadians (4) and continues to suck up resources that could be diverted elsewhere.

The metaphor of the 'war' on a particular disease is one that I dislike, but I do not know how else to declare that we are not winning the hepatitis $\mathrm{C}$ battle. The prevalence of chronic hepatitis $\mathrm{C}$ in Canada is increasing. The rate at which new immigrants from endemic areas of the world bring hepatitis $\mathrm{C}$ into Canada (approximately 2000 annually) and the rate at which injection drug users are newly infected (estimated 6600 annually) exceeds the rate at which currently infected individuals are cured (more than 1000 annually) or die (estimated 4700 annually from all causes). Thus, estimates of the number of patients with hepatitis $\mathrm{C}$ increased from approximately 240,000 to 250,000 over the period of 1998 to 2002 (4), and will continue to increase in the future, unless we can reduce the infection rate, or increase the cure rate.

University of Toronto, Toronto, Ontario

Correspondence: Dr Morris Sherman, University of Toronto, 585 University Avenue, Toronto, Ontario M5G 2N2. Telephone 416-340-4756, fax 416-591-2107, e-mail morris.sherman@uhn.on.ca

Received for publication February 5, 2008. Accepted February 6, 2008 
Hepatitis C is potentially curable in approximately $50 \%$ of those treated $(5,6)$. The cure rate will increase in the future with the introduction of oral small molecule inhibitors of viral functions, such as polymerase and protease inhibitors. However, under current circumstances only approximately 6000 patients are treated each year (based on the number of prescriptions collected by Brogan Inc, a health care consulting company) (Schering Plough Canada, personal communication).

Of the estimated 250,000 hepatitis C-infected individuals, only approximately 170,000 to 180,000 have been identified up to 2004, the last year for which there are data on the Public Health Agency of Canada (PHAC) Web site (7). Estimates are that only approximately 20,000 to 30,000 hepatitis Cinfected individuals have been treated (again, based on numbers of prescriptions written over the 15 years that treatment has been available) and it is likely that fewer than 10,000 have been cured. The reasons for the low cure rate are that many patients were treated with less-effective therapy before the introduction of pegylated interferon, an unknown number of prescriptions were for second and third courses of treatment, and treatment in the community has cure rates lower than those achieved in registration studies. Clearly, these low cure rates mean that a large number of patients remain at risk for liver failure and hepatocellular carcinoma. The symptomatic side effects of current treatment with pegylated interferon and ribavirin are a significant barrier to uptake of treatment, but even if oral effective therapy were to become immediately available, it would be years before the limited number of treating physicians in Canada could deal effectively with the volume of patients in need of therapy. However, for the foreseeable future, even with the advent of newer oral therapies, interferon and ribavirin will remain the mainstay of therapy and so, without measures to increase the uptake of therapy, the cure rate is not likely to increase substantially.

The figures given in the previous paragraphs are all estimates. The PHAC only collects minimal epidemiological data on hepatitis C. There is a graph on their Web site that claims to show hepatitis C incidence. Actually, what the graph shows is the number of new notifications each year. The vast majority of cases are not new cases, but represent cases of chronic hepatitis $\mathrm{C}$. Thus, this graph shows neither incidence nor prevalence of hepatitis $\mathrm{C}$. The PHAC also lumps hepatitis $\mathrm{C}$ in with surveillance for sexually transmitted diseases, probably one of the least common routes of transmission. If the PHAC cannot get it right, what hope is there for any kind of accurate, informative data collection? No general seroprevalence studies have been performed or planned; thus, we do not really know how many people are infected with hepatitis $\mathrm{C}$, nor is this information likely to be available soon. There are no data, only vague estimates, on the number of patients treated, and on the outcomes of that treatment. We do not really know how many people die of hepatitis C-related consequences; all we have are estimates of questionable accuracy. Statistics Canada has a chart of hepatitis $\mathrm{C}$ mortality (8) that is clearly inaccurate. For example, the chart claims that 69 deaths occurred as the result of acute hepatitis C in 2000, but only 10 deaths occurred as the result of chronic hepatitis $\mathrm{C}$ in the same year (8). This is hard to believe, because acute hepatitis $\mathrm{C}$ virtually never causes death. The site suggests that the mortality from chronic hepatitis $\mathrm{C}$ is in the range of 200 cases per year. This cannot be accurate. The PHAC gives the incidence of hepatocellular carcinoma for 2004 as 3.18 in a population of 100,000 , or 954 cases. If hepatitis $C$ accounts for $30 \%$ of that number, there may be approximately 200 deaths per year from this condition alone. Remis et al suggest that the hepatitis C mortality is much higher (4700 per year)(3).

The official ignorance regarding this important disease is part of a circle of neglect. The costs, and mortality and morbidity rates of hepatitis $\mathrm{C}$ do not cause alarm because they are below the radar as the result of improper measurements. Conversely, the perception seems to be that we do not need to measure hepatitis $\mathrm{C}$ statistics accurately because the numbers that are available are not alarming.

Yet, the data provided by Dr Myers and his colleagues are indeed cause for alarm. Morbidity, and therefore likely mortality, seem to be rising more rapidly than forecasted. As it is, the current hepatitis C-related health care burden is straining available resources. Care for patients with hepatitis is provided by the fewer than 100 hepatologists in Canada, some infectious disease physicians, gastroenterologists and internists, and a small number of family practitioners. Overall, there are probably not more than about 300 physicians in Canada who are providing treatment for hepatitis $\mathrm{C}$. The predicted increase in numbers of patients with the complications of hepatocellular carcinoma, who will require liver transplants will clearly outstrip our ability to provide care for these patients. Many experts have been predicting these grim scenarios for years. However, their warnings have for the most part fallen on deaf official ears. Experts have also recommended, for years, that hepatitis $\mathrm{C}$ needs a programmatic approach to decrease the rate of new infections, identify those already infected and provide effective therapy for those who need it. Only Ontario and British Columbia have established programs (underfunded and understaffed) to attempt to deal with the disease.

The data provided by Myers et al should serve as a wake-up call for provincial health authorities to pay more heed to hepatitis $\mathrm{C}$, and provide adequate funding to establish programs that will properly deal with this disease. An amount equivalent to $2 \%$ of that spent on compensation (ie, $\$ 40$ million) would be a good start!

\section{REFERENCES}

1. Pohani G, Zou S, Tepper M. Trends of hepatitis B and hepatitis C mortality in Canada, 1979-1997. Can J Public Health 2001;92:250-4.

2. Zou S, Tepper M, El Saadany S. Prediction of hepatitis C burden in Canada. Can J Gastroenterol 2000;14:575-80.

3. Remis R. Presentation to the Canadian Consensus Conference on Management of Viral Hepatitis. Toronto 2007.

4. Blajchman MA, Bull SB, Feinman SV. Post-transfusion hepatitis: impact of non-A, non-B hepatitis surrogate tests. Canadian Post-Transfusion Hepatitis Prevention Study Group. Lancet 1995;345:21-5.

5. Manns MP, McHutchison JG, Gordon SC, et al. Peginterferon alfa-2b plus ribavirin compared with interferon alfa-2b plus ribavirin for initial treatment of chronic hepatitis C: A randomised trial. Lancet 2001;358:958-65.

6. Fried MW, Shiffman ML, Reddy KR, et al. Peginterferon alfa-2a plus ribavirin for chronic hepatitis $C$ virus infection. N Engl J Med 2002;347:975-82.

7. Public Health Agency of Canada. Disease surveillance on-line. $<$ http://dsol-smed.phac-aspc.gc.ca/> (Version current at February 28, 2008).

8. Statistics Canada. CANSIM Table 102-0521 - Deaths, by cause, Chapter I: Certain infectious and parasitic diseases (A00 to B99), age group and sex, Canada, annual (number). $<$ http://cansim2.statcan.ca/cgi-win/CNSMCGI.PGM > (Version current at Feberuary 28, 2008). 


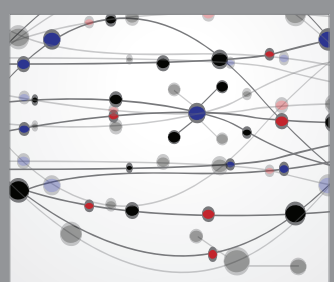

The Scientific World Journal
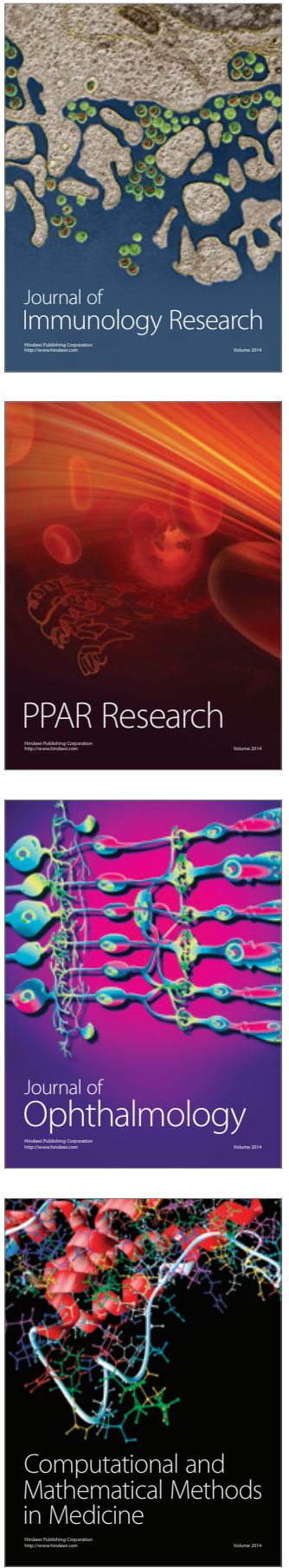

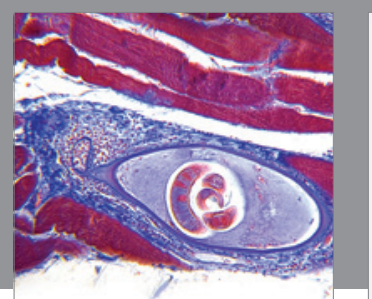

Gastroenterology Research and Practice

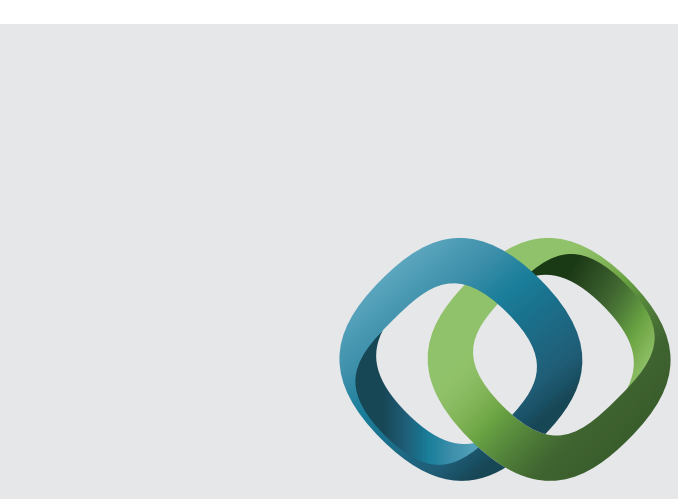

\section{Hindawi}

Submit your manuscripts at

http://www.hindawi.com
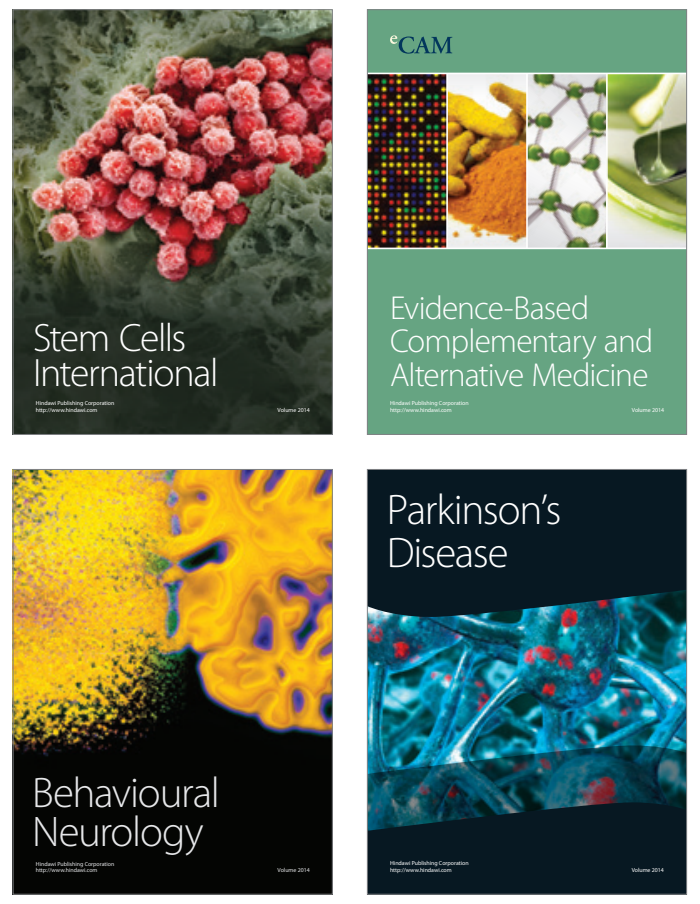
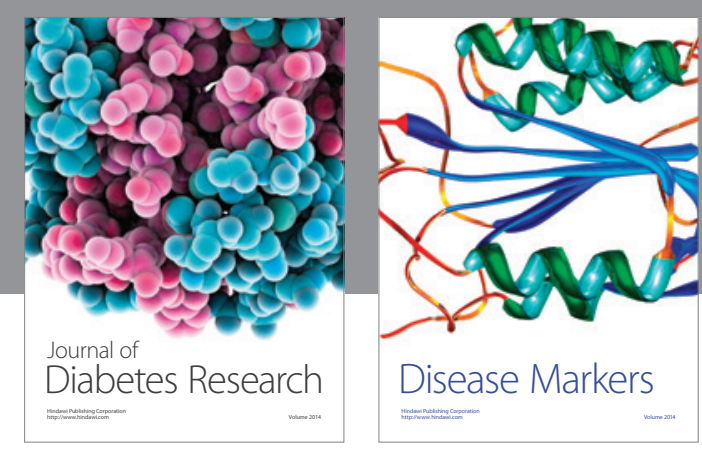

Disease Markers
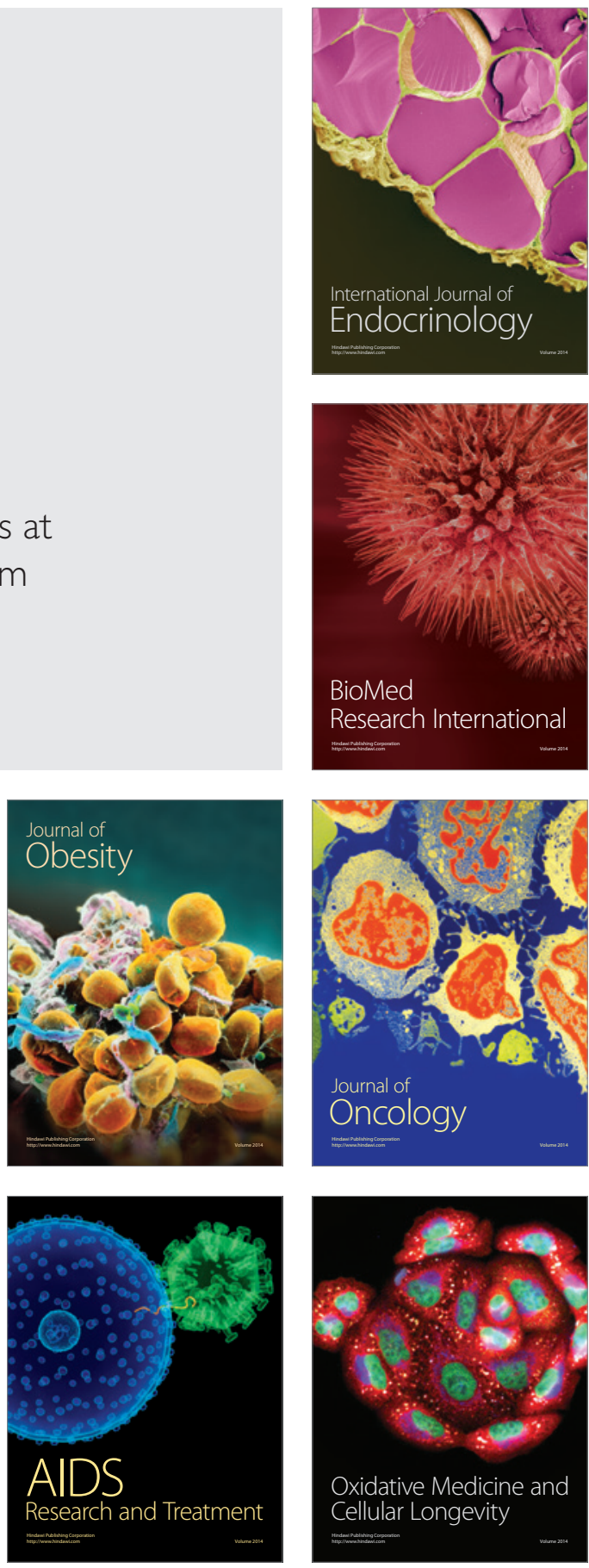